\title{
Point-of-purchase health information encourages customers to purchase vegetables: objective analysis by using a point-of-sales system
}

\author{
Yoshiko Ogawa • Naohito Tanabe · Akiko Honda • \\ Tomoko Azuma • Nao Seki • Tsubasa Suzuki • \\ Hiroshi Suzuki
}

Received: 6 April 2010/Accepted: 1 November 2010/Published online: 10 December 2010

(c) The Japanese Society for Hygiene 2010

\begin{abstract}
Objectives Point-of-purchase (POP) information at food stores could help promote healthy dietary habits. However, it has been difficult to evaluate the effects of such intervention on customers' behavior. We objectively evaluated the usefulness of POP health information for vegetables in the modification of customers' purchasing behavior by using the database of a point-of-sales (POS) system.

Methods Two supermarket stores belonging to the same chain were assigned as the intervention store (store I) and control store (store C). POP health information for vegetables was presented in store I for 60 days. The percent increase in daily sales of vegetables over the sales on the same date of the previous year was compared between the stores by using the database of the POS system, adjusting for the change in monthly visitors from the previous year (adjusted $\Delta$ sales).

Results The adjusted $\Delta$ sales significantly increased during the intervention period (Spearman's $\rho=0.258, P$ for trend $=0.006$ ) at store I but did not increase at store $\mathrm{C}$
\end{abstract}

Y. Ogawa · A. Honda · T. Azuma

Niigata Prefectural Government, Niigata, Japan

N. Tanabe $(\bowtie) \cdot$ A. Honda $\cdot$ T. Suzuki

Division of Health Promotion, Niigata University Graduate

School of Medical and Dental Sciences, 1-757 Asahimachi-dori,

Chuo Ward, Niigata 951-8510, Japan

e-mail: tanabe@med.niigata-u.ac.jp

N. Seki

School of Health Sciences, Faculty of Medicine,

Niigata University, Niigata, Japan

H. Suzuki

Department of Nursing, Niigata Seiryo University,

Niigata, Japan $(\rho=-0.037, P$ for trend $=0.728)$. The growth of the mean adjusted $\Delta$ sales of total vegetables from 30 days before the intervention period through the latter half of the intervention period was estimated to be greater at store I than at store $\mathrm{C}$ by 18.7 percentage points ( $95 \%$ confidence interval 1.6-35.9).

Conclusions Health-related POP information for vegetables in supermarkets can encourage customers to purchase and, probably, consume vegetables.

Keywords Point-of-purchase information - Vegetables . Intervention · Point-of-sales system · Behavior modification

\section{Introduction}

A diet rich in vegetables is associated with reduced risk of cancer [1] and cardiovascular disease (CVD) [2, 3]. The Japanese government has been urging its adult population to eat more than $350 \mathrm{~g}$ of vegetables a day on average [4]. However, the average daily intake has slightly decreased from $292 \mathrm{~g}$ in 1997 [4] to $290 \mathrm{~g}$ in 2007 [5]; thus, a more effective approach to promote vegetable intake is required.

Providing point-of-purchase (POP) information can be a cheap and useful measure to promote healthy lifestyle habits [6, 7]. In terms of improving dietary habits, POP information at supermarkets where residents usually purchase foods could be effective. However, it has been difficult to objectively evaluate the effects of such interventions on customers' behavior.

Along with the rapid development of computer systems in the past decades, use of point-of-sales (POS) systems has become very popular in Japan [8]. In a POS system, daily sales are managed, and each transaction is recorded. 
By using this system, sales trends in a store can be analyzed objectively.

This study was conducted to clarify how POP health information for vegetables encourages customers to purchase vegetables, by using the database from a POS system.

\section{Materials and methods}

We selected two supermarket stores that belong to the same chain, located in a city (Gosen City) and a neighboring town (Tagami Town) in Niigata Prefecture, Japan, as the study fields: one was assigned to be the intervention store (store I) and the other to be the control store (store C) (Table 1). Store I is located on the rim of a sub-center area of Gosen City, whereas store C is located in a border area of Tagami Town. According to an impression of a staff member of the supermarket chain, visitors of store $\mathrm{C}$ appear to be younger than visitors of store I, because the marketing zone of store $\mathrm{C}$ includes a recently developed residential area, a junior college, and a university. However, there were no significant changes in the characteristics of the marketing zones or visitors of either store in 2006 or 2007 . The sales floor area and average daily visitors were $2,912 \mathrm{~m}^{2}$ and 1,684 , respectively, for store I and $757 \mathrm{~m}^{2}$ and 1,098, respectively, for store C. Although the sizes of the stores are different, the varieties of food displayed are similar, and items are similarly priced in both stores, because they both belong to the same supermarket chain. During the latter half of the study period, that is, in October and November, the number of total monthly visitors increased at store I compared with the same months of the previous year (2006), as seen from the statistics provided by the supermarket chain, and decreased at store C. The effects of such changes in the number of visitors were taken into account in the statistical analyses.

The 90-day study period from August 14 to November 11 in 2007 was divided into three 30-day periods: the preintervention stage, early intervention stage, and late intervention stage. Health and nutrition information related to consumption of vegetables was displayed as POP health information only at store I during the intervention stages. POP health information for fruits was also displayed at store I. However, a caution against overeating was added to the information for fruits, and the display space was restricted so as not to affect purchasing behavior too much. Then, we examined the effects of the intervention on customers' purchasing behavior by comparing the sales data recorded in the POS system for the two stores.

\section{POP information}

A4- and A5-sized posters were prepared for vegetables and fruits, respectively. In order to convey vegetables' preventive effects against lifestyle-related diseases, we used our original posters and those created by the National Institute of Health and Nutrition. The main contents were (1) disease prevention effects of vegetables, (2) nutrients in vegetables and their functions, (3) information about seasonal vegetables, and (4) recipes for low-calorie meals rich in vegetables. Five posters were placed in display spaces for vegetables. In addition, posters were displayed at all eight checkout counters so that they could be noticed by all customers. The contents of the posters at the checkout counters were changed every 2 weeks to maintain customers' interest.

For fruits, we displayed one version of our original poster at two points on the fruit display floor to be noticed only by customers who were buying fruits. In addition to the lifestyle disease prevention effects of fruits, we included information on how to prevent overeating, which could lead to obesity and hyperlipidemia. In Japan, obesity prevention is a public-health policy priority, and therefore, increasing fruit consumption is not a priority measure in Japan's health promotion strategy.

\section{Extraction of sales data from the POS system}

Daily sales data for vegetables and fruits were extracted from the database of the POS system for all days during the study period and for the same dates in the previous year.
Table 1 Characteristics of the investigated stores

Store I intervention store; Store $C$ control store. Both stores belong to the same chain and are located in a city and neighboring town in Niigata Prefecture, Japan

\begin{tabular}{lll}
\hline & Store I & Store C \\
\hline Location & Sub-center of Gosen City & Suburb of Tagami Town \\
Floor area & $2,912 \mathrm{~m}^{2}$ & $757 \mathrm{~m}^{2}$ \\
Average daily visitors & 1,684 & 1,098 \\
Relative changes in monthly visitors & 2007 from 2006 \\
August & 0.984 & \\
September & 1.046 & 0.960 \\
October & 1.007 & 1.001 \\
November & 1.051 & 0.995 \\
\hline
\end{tabular}


Table 2 Classification of vegetables and fruits with typical examples

\begin{tabular}{ll}
\hline Classification & Examples \\
\hline Vegetables & $\begin{array}{l}\text { Spinach, garland chrysanthemum, turnip } \\
\text { green, cabbage, etc. } \\
\text { Lettuce, red leaf lettuce, cauliflower, } \\
\text { broccoli, celery, etc. }\end{array}$ \\
Fruit and flower & $\begin{array}{l}\text { Tomato, eggplant, cucumber, sweet pepper, } \\
\text { okra, etc. }\end{array}$ \\
Root & $\begin{array}{l}\text { Turnip, Japanese radish, carrot, onion, } \\
\text { burdock, etc. }\end{array}$ \\
Juice & $\begin{array}{l}\text { Tomato juice, mixed vegetable juice, mixed } \\
\text { vegetable and fruit juice, etc. }\end{array}$ \\
Other & $\begin{array}{l}\text { Mushroom, bamboo shoots, soy bean sprouts, } \\
\text { royal fern, bracken, etc. }\end{array}$ \\
Fruits & Fresh fruits and dried fruits
\end{tabular}

This classification is based on the classification that was set up in the point-of-sales system of the investigated stores

For vegetables, the categorical summary (Table 2) was also extracted; the categories had been formulated specifically for sales management in the POS system, and thus they did not correspond to scientific classification. Sales data in this study are presented in Japanese yen $(115.4$ yen $=1$ US dollar as of the end of September 2007).

\section{Statistical analysis}

The percent increase in sales of fruits and vegetables from sales on the same date in the previous year $(\Delta$ sales $)$ was calculated for every day of the study period for each store and averaged for three 30-day periods: the pre-intervention stage, early intervention stage, and late intervention stage. The mean percent change values calculated from individual daily sales data are theoretically not equal to the percent change values calculated from mean daily sales, because the reference values (values of sales in 2006) fluctuated every day. There are strong seasonal influences on the price and variety of commercially distributed vegetables and fruits in Japan. This seasonality in price and variety can affect the seasonality in sales as well. Consequently, gross sales amounts themselves do not necessarily show the amount of purchased vegetables and fruits. Therefore, we used the percent change in sales from the previous year. Since percent change data are calculated on the basis of sales data from the same date (i.e., the same season) of the previous year, they are less likely to be affected by such seasonality. In addition, percent change is not affected by the size of the stores. Other factors such as harvest size and the amount of imports can also affect prices; this is one reason why we need control data from store C. To control for the effects of changes in the number of visitors from the previous year, adjusted sales for each day of 2007 were calculated for each store by dividing actual sales for a day by the relative change in visitors for the month. Adjusted $\Delta$ sales was also calculated using the adjusted sales from 2007.

The trend change of $\Delta$ sales as the stages advanced was evaluated by using the Spearman's rank correlation coefficient $(\rho)$. To evaluate the effects of the intervention on changes in mean $\Delta$ sales from the pre-intervention stage to the early and late intervention stages, interaction estimates between intervention status and stages and their 95\% confidence intervals (CI) were calculated with linear regression models in which stages were included as two dummy variables so that the pre-intervention stage is a reference category. It follows that the interaction estimate for each intervention stage is equal to (mean $\Delta$ sales in the given intervention stage - mean $\Delta$ sales in the pre-intervention stage at store I) - (mean $\Delta$ sales in the given intervention stage - mean $\Delta$ sales in the pre-intervention stage at store C). The distributions of $\Delta$ sales of vegetables and fruits appeared to be close to a normal distribution. Furthermore, the skewness $(P=0.170$ for total vegetables, $P=0.187$ for fruits $)$ and kurtosis $(P=0.310$ for total vegetables, $P=0.667$ for fruits) of these distributions were statistically insignificant. Therefore, we applied parametric procedures to evaluate the intervention effects on $\Delta$ sales.

SPSS-J version 11 (SPSS Japan Inc., Tokyo, Japan) for Windows was used for all statistical analyses, and statistical significance was set at two-tailed $P<0.05$.

\section{Results}

Mean adjusted $\Delta$ sales of total vegetables at store I increased as the stages advanced $(\rho=0.285, P$ for trend $=0.006$ ) (Table 3), whereas at store $\mathrm{C}$ it $\operatorname{did} \operatorname{not}(\rho=-0.037, P$ for trend $=0.728$ ). Analysis by classification of vegetables at store I revealed significant growth in $\Delta$ sales in all categories of vegetables ( $\rho$ ranged from 0.280 for juice to 0.396 for green leafy vegetables, $P$ for trend $<0.05$ ) except for leafy vegetables $(\rho=-0.079, P$ for trend $=0.459)$ and root vegetables $(\rho=0.206, P$ for trend $=0.052)$. At store $\mathrm{C}$, $\Delta$ sales significantly increased only for "other vegetables" $(\rho=0.282, P$ for trend $=0.007)$, and it significantly decreased for leafy vegetables $(\rho=-0.313, P$ for trend $=0.003$ ). Mean $\Delta$ sales of fruits did not show a significant trend change in either store I or store C.

A significant intervention effect on adjusted $\Delta$ sales of total vegetables was observed in the late intervention stage (estimate 18.7, 95\% CI 1.6-35.9); that is, the growth of mean adjusted $\Delta$ sales of total vegetables from the preintervention to the late intervention stages was estimated to be greater at store I than at store $\mathrm{C}$ by 18.7 percentage 


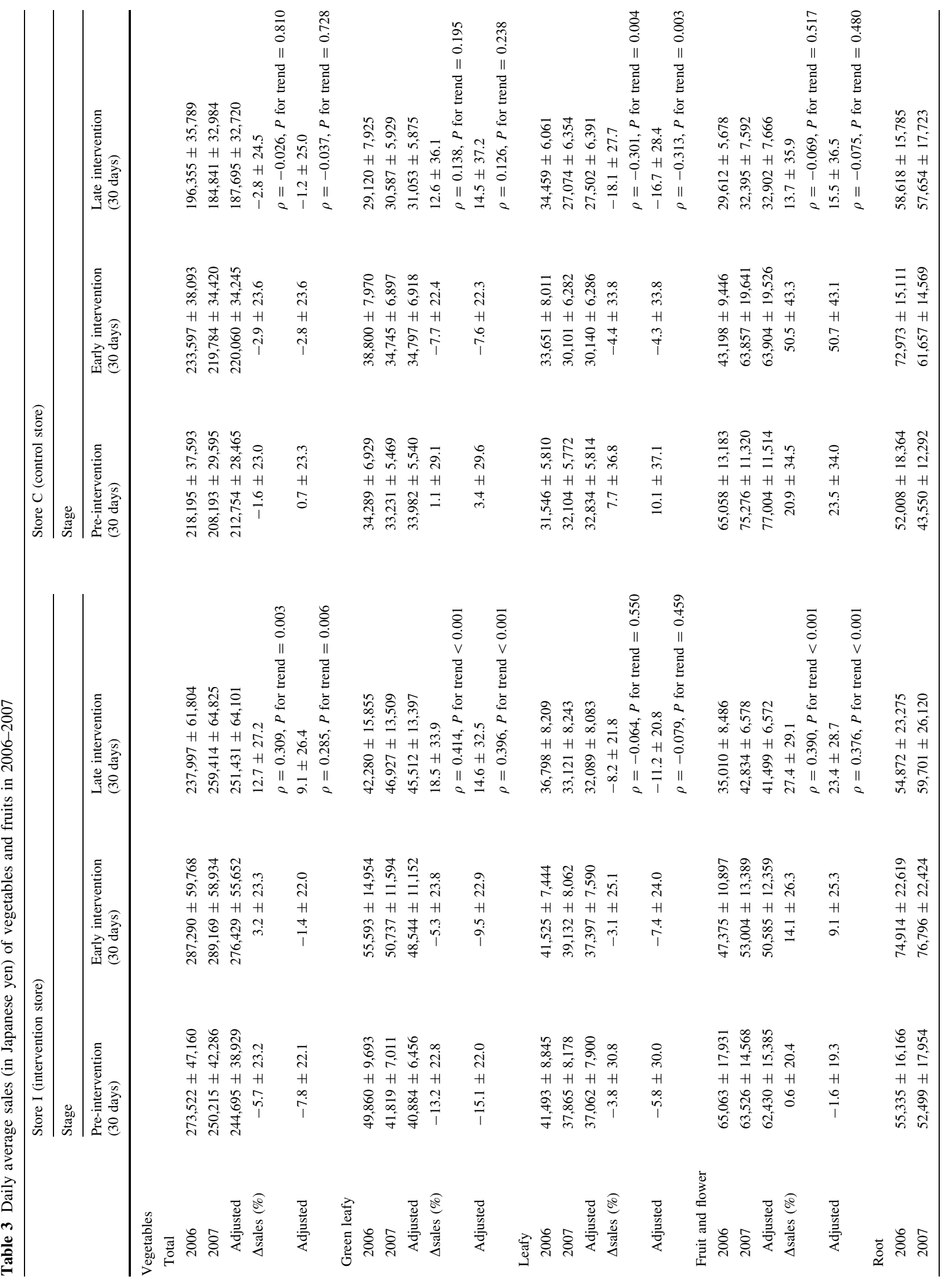




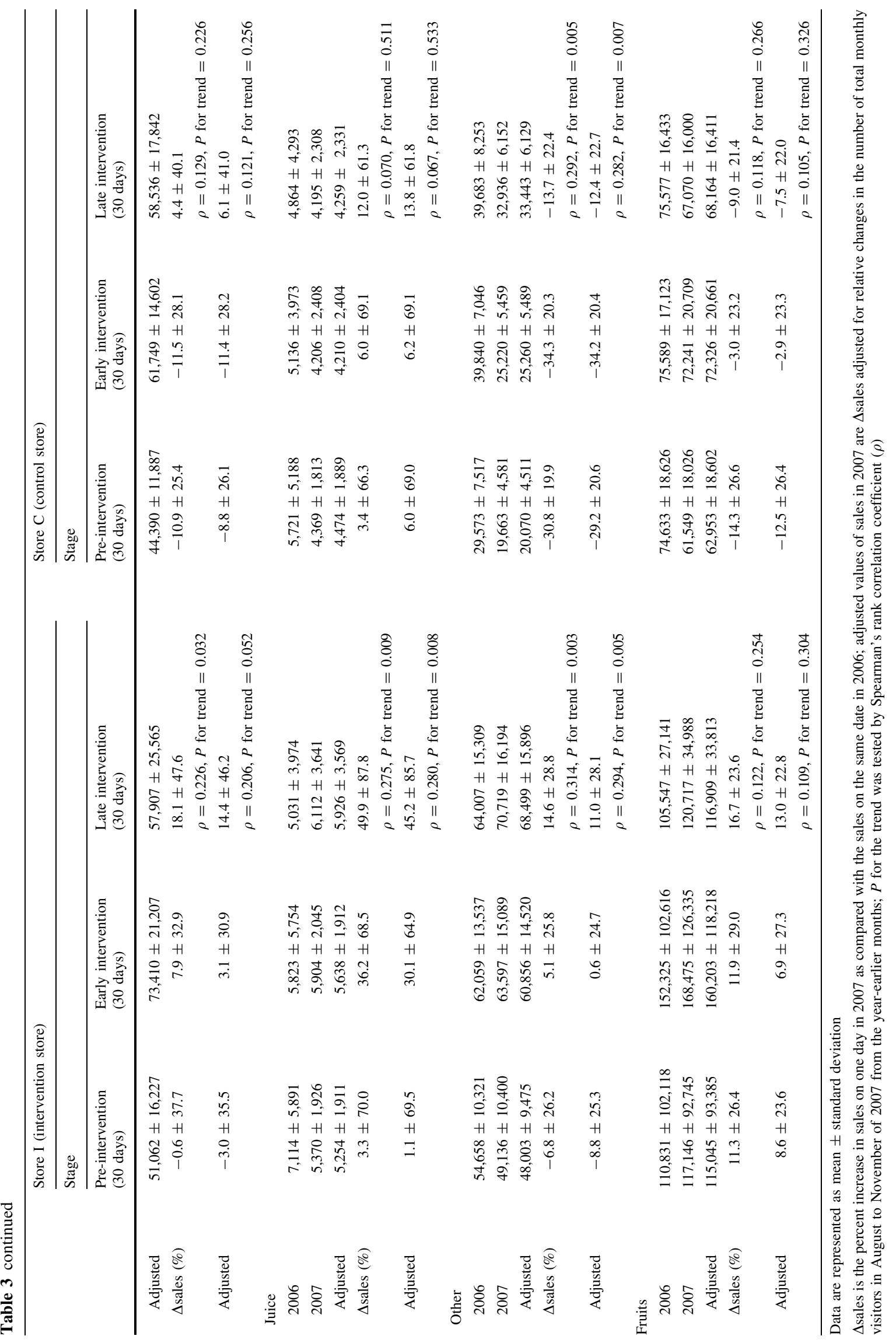


Table 4 Intervention effects on $\Delta$ sales of vegetables and fruits

The interaction estimate between the intervention status and study periods on $\Delta$ sales in a linear regression model was assessed as an intervention effect. The estimate for each intervention period is equal to (mean $\Delta$ sales in the given intervention stage - mean $\Delta$ sales in the pre-intervention stages at store I) - (mean $\Delta$ sales in the given intervention stage - mean $\Delta$ sales in the preintervention stage at store $\mathrm{C}$ ), which can be calculated from values in Table 3. $* P<0.05$, ${ }^{\dagger} P<0.01$

Adjusted estimates were calculated based on adjusted sales in 2007, which are described in Table 3

\begin{tabular}{|c|c|c|c|c|}
\hline & \multicolumn{2}{|c|}{ Early intervention } & \multicolumn{2}{|c|}{ Late intervention } \\
\hline & Estimates & $95 \% \mathrm{CI}$ & Estimates & $95 \% \mathrm{CI}$ \\
\hline \multicolumn{5}{|l|}{ Vegetables } \\
\hline Total & 10.2 & -7.2 to 27.7 & 19.6 & 2.2 to $37.1^{*}$ \\
\hline Adjusted & 9.8 & -7.3 to 27.0 & 18.7 & 1.6 to $35.9^{*}$ \\
\hline Green leafy & 16.7 & -3.9 to 37.3 & 20.2 & -0.3 to 40.8 \\
\hline Adjusted & 16.6 & -3.8 to 37.1 & 18.6 & -1.8 to 39.0 \\
\hline Leafy & 12.8 & -8.7 to 34.2 & 21.4 & -0.1 to 42.8 \\
\hline Adjusted & 12.8 & -8.5 to 34.1 & 21.4 & 0.1 to $42.7 *$ \\
\hline Fruit and flower & -16.1 & -39.4 to 7.3 & 34.1 & 10.7 to $57.4^{\dagger}$ \\
\hline Adjusted & -16.5 & -39.6 to 6.7 & 33.0 & 9.9 to $56.2^{\dagger}$ \\
\hline Root & 9.1 & -16.9 to 35.2 & 3.4 & -22.6 to 29.4 \\
\hline Adjusted & 8.6 & -16.9 to 34.0 & 2.4 & -23.1 to 27.8 \\
\hline Juice & 30.3 & -20.8 to 81.5 & 38.0 & -13.2 to 89.1 \\
\hline Adjusted & 28.9 & -21.9 to 79.6 & 36.4 & -14.4 to 87.1 \\
\hline Other & 15.5 & -1.9 to 32.9 & 4.4 & -13.0 to 21.7 \\
\hline Adjusted & 14.4 & -2.7 to 31.5 & 3.0 & -14.2 to 20.1 \\
\hline Fruits & -10.7 & -28.9 to 7.4 & 0.1 & -18.1 to 18.2 \\
\hline Adjusted & -11.4 & -28.9 to 6.1 & -0.7 & -18.2 to 16.9 \\
\hline
\end{tabular}

points (Table 4). Significant positive intervention effects on adjusted $\Delta$ sales were also observed for leafy vegetables (estimate 21.4, 95\% CI 0.1-42.7) and for fruit and flower vegetables (estimate 33.0, 95\% CI 9.9-56.2).

\section{Discussion}

Our objective analyses using the POS system revealed that POP health information in supermarket stores could encourage customers to purchase vegetables. Purchased vegetables are expected to be consumed by the customers themselves and probably by their relatives. Thus, POP health information could help in healthy behavior modification in the field of diet and nutrition.

The intervention effect on $\Delta$ sales was most apparent for fruit and flower vegetables. In Japan, tomatoes, eggplant, cucumbers, and okra are very popular fruit and flower vegetables, also known as summer vegetables. The production and distribution as well as sales of these fruit and flower vegetables decrease during the fall and winter seasons. In this study, although sales of fruit and flower vegetables decreased over the intervention period in both stores, the rate of the decrease could have been diminished by the POP information about recipes that use these vegetables. Although we do not have sales data on individual vegetables, we speculate that our POP information might have affected sales of tomatoes. This is because tomatoes can be eaten raw and therefore can be served easily in daily meals.
A significant intervention effect was also found for leafy vegetables. Most leafy vegetables are low in calories, easy to prepare, very popular for use in salads, and available throughout the year. These characteristics might have encouraged customers to choose leafy vegetables when they bought vegetables. However, the intervention effects were positive for all varieties of vegetables, although the intervention effects for some varieties were not statistically significant. Therefore, we believe that our POP information positively affected the decision to purchase vegetables in general.

In previous studies, the effects of nutritional environment intervention through POP information have been inconsistent. In the review by Seymour et al. [9], the success rate of increasing targeted items was higher in worksites and universities than in grocery stores. The authors suggested that the limited food choices available for workers or students in on-site eating establishments and vending machines might have contributed to the successful results in worksites and universities. Although the authors concluded that intervention in grocery stores appeared to be the least effective, five of eight studies that used information strategies in grocery stores reported increased sales of some targeted items. Most studies featured in that review chose multiple target items for POP information, whereas ours emphasized the health effects of vegetables. The fact that this study chose a clear target might have contributed to its finding that the intervention was successful. 
Buscher et al. [6] reported that $89 \%$ of cafeteria users in a university recognized POP information at the entrance, whereas only $7 \%$ of users recognized POP information at a good display space. We placed POP information not only on the vegetable display floor but also at the checkout counters. These display procedures that targeted all customers could also have affected even those customers who were not initially interested in consuming vegetables. The paper by Buscher et al. found that POP information failed to encourage customers to purchase vegetables, unlike in our study. This difference in results could be explained in part by differences in target population and methodology. The target population of POP information in that paper was university students, whereas ours was general customers living near supermarket stores. Our target population could be more sensitive to health-related POP information than young university students because they would have responsibility for preparing meals not only for themselves, but also for their family members. The duration of POP information displayed for vegetables also differed between the two studies. Buscher et al. changed the target foods of POP information every week, and POP information for vegetables was displayed during the first week of their 6-week intervention period. In our study, intervention effects of POP information were not observed during the first 4 weeks of the intervention period. In order to alter customers' purchasing behavior for vegetables, continuous provision of POP information for at least 4 weeks would be necessary.

Hirayama et al. [10] reported that, historically, consumption of green-yellow vegetables was associated with reduced risk of mortality from cancer of the stomach, colon, lung, cervix, and prostate. A recent Japanese largescale cohort study also reported reduced risk of gastric cancer associated with vegetable intake [11], although this study failed to demonstrate reduced risk of cancer of the lung, colorectum, and prostate. According to some Japanese cohort studies, vegetable intake is negatively associated with risk of mortality from total CVD [12] and stroke [13]. Therefore, the population strategy to promote vegetable intake through POP information at food stores could contribute to reduction of mortality from gastric cancer and CVD in the Japanese population.

While we mainly targeted vegetables for promotion, fruits also have the potential to contribute to prevention of cancer [1] and CVD [3]. However, promoting fruit consumption is not a priority measure in Japan's public health strategy [4]. According to observational studies, a fruit-rich diet is negatively associated with obesity [14, 15]. However, these studies found that subjects who ate more fruits got less energy from other food items. In the study by Vioque et al. [15], total energy intake was adjusted in multivariable models. Consequently, their study suggests that a high level of fruit consumption could contribute to obesity prevention if total energy intake were to remain unchanged. There is no guarantee that adding energy intake from fruits without reducing energy intake from other food items would not lead to obesity. Fructose in fruits can also cause visceral adiposity, dyslipidemia, and insulin resistance [16]. These are the reasons why we prepared fewer posters on fruits than on vegetables and placed them only at the fruit display space. Cautions against overeating were also provided. Consequently, as we expected in advance, $\Delta$ sales did not rise even at store I. How fruit consumption can be promoted without causing adverse effects owing to overeating will be a future concern.

Another aspect of this study is the use of the POS system as a source of research data. The system immediately records all sales data by reading barcodes on purchased goods at checkout counters. Using this database, one can analyze complete sales data at a store, as we did for vegetables and fruits. Furthermore, since the data include no personal information about customers, the ethical barrier in collecting such data for research is low. Thus, the POS system is expected to be highly useful in epidemiological study in the future.

Our study has several limitations. First, the number of stores in the study was too small: only one store was given intervention and one store was observed as a control. To confirm the universality of our results, larger-scale randomized studies are necessary.

Second, the long-term effects of the POP health information were not analyzed. This would have been difficult for us, because store $\mathrm{C}$ started to provide POP information after our study was completed. Therefore, the long-term effects could not be investigated owing to the loss of control data. Since it is ethically difficult to leave customers of control stores blind for useful information, analyzing the long-term effects remains a methodological challenge.

Third, $\Delta$ sales of fruits was positive at store $C$, whereas it was negative at store I throughout the study period. We cannot deny the possibility that some sales promotion had been carried out at store $\mathrm{C}$ before this study was started, although there remain no records or memory of such promotion. However, we asked the stuff members of both stores not to conduct different promotions between the stores during the study period other than our POP information display in store I. For the present study, the most important finding for fruit sales is that the changing patterns of $\Delta$ sales were not significantly different between the stores. This finding shows that the POP information for fruits in store I had no significant effect on the purchasing behavior of customers.

Fourth, we cannot conclude that our procedure would be applicable to a non-Japanese population, because types of 
diet, grocery shopping systems, and the educational backgrounds of customers vary between countries.

In conclusion, as we have shown in the case of purchasing behavior for vegetables, POP health information could help promote healthy dietary habits. Larger randomized studies, not only in Japan but also in other countries, would be necessary to confirm the universality of our results. The POS system can provide objective and accurate research data for such epidemiological studies.

Acknowledgments We express our sincere appreciation to the managers and staff members of the supermarket chain and its stores for their cooperation.

\section{References}

1. American Institute for Cancer Research. Vegetables, fruits, pulses (legumes), nuts, seeds, herbs, spices. In: World Cancer Research Fund and American Institute for Cancer Research, editors: food, nutrition, physical activity, and the prevention of cancer: a global perspective. Washington DC: American Institute for Cancer Research; 2007. p. 75-115.

2. Dauchet L, Amouyel P, Hercberg S, Dallongeville J. Fruit and vegetable consumption and risk of coronary heart disease: a meta-analysis of cohort studies. J Nutr. 2006;136:2588-93.

3. He FJ, Nowson CA, MacGregor GA. Fruit and vegetable consumption and stroke: meta-analysis of cohort studies. Lancet. 2006;367:320-6.

4. Ministry of Health, Labour and Welfare. National health promotion movement in the 21st century (Healthy Japan 21). Tokyo: Japan Health Promoting \& Fitness Foundation; 2000 (in Japanese).

5. Ministry of Health, Labour and Welfare. Outline for the results of the 2007 National Health and Nutrition Survey (in Japanese). http://www.mhlw.go.jp/houdou/2008/12/h1225-5.html (Accessed 19 Oct 2010).

6. Buscher LA, Martin KA, Crocker S. Point-of-purchase messages framed in terms of cost, convenience, taste, and energy improve healthful snack selection in a college foodservice setting. J Am Diet Assoc. 2001;101:909-13.

7. Yoshita K, Tanaka T, Kikuchi Y, Takebayashi T, Okamura T, Ueshima H. HIPOP-OHP research group. The evaluation of materials to provide health-related information as a population strategy in the worksite: the High-risk and Population Strategy for Occupational Health Promotion (HIPOP-OHP) Study. Environ Health Prev Med. 2004;14:111-7.

8. Takizawa M. Summary report of the 2007 survey on computerization of marketing management system. Ryutsu Shisutemu. 2008;136:74-9. (in Japanese).

9. Seymour JD, Yaroch AL, Serdula M, Blanck HM, Khan LK. Impact of nutrition environmental interventions on point-of-purchase behavior in adults: a review. Prev Med. 2004;39(Suppl 2):S108-36.

10. Hirayama T. Life-Style and cancer: from epidemiological evidence to public behavior change mortality reduction of target cancers. J Natl Cancer Inst Monogr. 1992;12:65-74.

11. Kobayashi M, Tsubono Y, Sasazuki S, Sasaki S, Tsugane S, JPHC Study Group. Vegetables, fruit and risk of gastric cancer in Japan: a 10-year follow-up of the JPHC Study Cohort I. Int J Cancer. 2002;102:39-44.

12. Nagura J, Iso H, Watanabe Y, Maruyama K, Date C, Toyoshima $\mathrm{H}$, et al. Fruit, vegetable and bean intake and mortality from cardiovascular disease among Japanese men and women: the JACC Study. Br J Nutr. 2009;102:285-92.

13. Sauvaget C, Nagano J, Allen N, Kodama K. Vegetable and fruit intake and stroke mortality in the Hiroshima/Nagasaki Life Span Study. Stroke. 2003;34:2355-60.

14. Bradlee ML, Singer MR, Qureshi MM, Moore LL. Food group intake and central obesity among children and adolescents in the Third National Health and Nutrition Examination Survey (NHANES III). Public Health Nutr. 2009;22:1-9.

15. Vioque J, Weinbrenner T, Castelló A, Asensio L, Garcia de la Hera M. Intake of fruits and vegetables in relation to 10-year weight gain among Spanish adults. Obesity (Silver Spring). 2008;16:664-70.

16. Stanhope KL, Havel PJ. Fructose consumption: potential mechanisms for its effects to increase visceral adiposity and induce dyslipidemia and insulin resistance. Curr Opin Lipidol. 2008;19: $16-24$. 